\title{
Cell proliferation in the human gallbladder epithelium: effect of distension
}

\author{
Ph. PUTZ AND G. WILlEMS \\ From the Gastroenterological Research Unit, Vrije Universiteit Brussel and the Department of Surgery, \\ St Pierre Hospital, Brussels, Belgium
}

SUMMARY DNA synthesis activity in the epithelium of the human gallbladder was studied through in vitro labelling of mucosal specimens with ${ }^{3} \mathrm{H}$-thymidine and autoradiography. The specimens were taken at the time of a surgical operation. Eight 'normal' gallbladders and six distended gallbladders from patients with carcinomatous obstruction of the common bile duct were examined. Proliferative activity was very low in the normal and significantly higher in the distended gallbladders.

The use of labelled precursors of DNA and of autoradiography has allowed the study of cell proliferation in the gallbladder of experimental animals. Recent studies have reported an increased incorporation of ${ }^{3} \mathrm{H}$-thymidine in the epithelium of the gallbladder after ligation of the common bile duct (Scott, 1974) and during administration of lincomycin (Scott, 1976) or of a lithogenic diet (Scott, 1978) to rodents. The study of cell renewal in the normal human gallbladder has not been undertaken because ethical considerations stood in the way of injecting patients with tritiated thymidine. However, the in vitro labelling of surgical specimens with tritiated thymidine makes it possible to observe and to count the cells in DNA synthesis in biopsy specimens without previous injection of radiolabelled compounds (Willems et al., 1970). This method was recently applied to human gallbladders and permitted the observation that epithelial cell proliferation in this organ is significantly increased in patients with gall stones (Putz and Willems, 1978).

In the present work, in vitro labelling was used for observing the changes in proliferative activity in the human gallbladder under the effect of distension. Adequate conditions for this study in man were found in surgical patients with complete obstruction of the distal bile duct by a malignant tumour.

\section{Methods}

\section{SPECIMENS}

The gallbladders from five patients with a cancer of the head of the pancreas and one patient with a

Received for publication 9 October 1978 malignant ampulloma were used for this study. Obstructive jaundice and an increasingly distended gallbladder were observed in all patients. The patency of the cystic duct and the complete obstruction of the distal choledocus were verified by preoperative cholangiography. Five of the patients underwent a palliative cholecystoduodenostomy, and a $1 \times 0.5 \mathrm{~cm}$ piece of the gallbladder wall was excised by the surgeon at the site of the future anastomosis. In one patient a cholecystectomy and a duodenopancreatectomy were performed; a similar piece of the gallbladder wall was taken in this case immediately after the cholecystectomy was done.

Eight human gallbladders that were considered to be 'normal' by the surgeon (one of us) were taken as controls; three of them were resected during right hepatectomies, one was taken within three minutes after death in a patient with a ruptured abdominal aneurysm and four came from decerebrated donors of kidney grafts and were excised immediately after bilateral nephrectomy. All these gallbladders were flaccid at the time of surgery and contained no stones. No histological signs of inflammation were found during microscope examination.

\section{AUTORADIOGRAPHIC TECHNIQUE}

The mucosa of the gallbladder specimen was immediately separated from the submucosa with scissors rinsed in saline, divided into $1 \mathrm{~mm}$ wide strips with a scalpel, and incubated for 15 minutes in a shaking water bath at $37^{\circ} \mathrm{C}$ in Earle's medium (BME-Diploid; General Biochemicals, Chagrin Falls, Ohio) containing $10 \%$ calf serum and $20 \mu$ $\mathrm{Ci} / \mathrm{ml}$ tritiated thymidine. As described for other tissues (Willems et al., 1972), the pH was maintained 
at 7.4 by carbogen bubbling throughout incubation.

Specimens from each gallbladder were fixed in acetic alcohol, then mounted within paraffin blocks and cut 3 to $4 \mu$ thick. Sections were prestained with periodic acid-Schiff (PAS) and then dipped into nuclear emulsion (Ilford $\mathrm{K} 5$ in gel form). The autoradiographs were stored at $4^{\circ} \mathrm{C}$, developed after 18 days, and counterstained with haematoxylin.

Some labelled strips from distended gallbladders were embedded in Epon and cut at 1.8 $\mu$ thickness in order to increase the resolution of the autoradiographs and to avoid superimposition of the nuclei. The Epon sections were stained with toluidine blue $\mathrm{pH} 9 \cdot 2$ after developing the autoradiographs.

\section{LABELLING AND MITOTIC INDICES}

Before some sections from the labelled specimens were dipped into the nuclear emulsion, they were dipped into a pH 7.6 buffer with $0.002 \%$ deoxyribonuclease (DNAse from pancreas; Merck, Darmstadt) for two hours at $37^{\circ} \mathrm{C}$. Corresponding sections were dipped into the buffer without DNAse.

In the paraffin sections from each specimen 1797 to 3203 consecutive epithelial cells over the hills and valleys of the mucosal folds were counted and the percentages of labelled nuclei (labelling index) and of mitotic figures (mitotic index) were counted. Only cells located above a visible basement membrane were considered. Cells were considered labelled when more than 5 grains overlaid the nuclei. Our low background grain counts and the fact that the vast majority of the labelled cells were overlain by more than 30 grains per nucleus ensured that this criterion was suitable.

\section{Results}

The labelling index in the normal gallbladder epithelium was very low (mean $0.16 \% \pm 0.05$ ) and was significantly $(P<0.01)$ higher in the specimens taken from the distended gallbladders (mean $0.66 \%$ \pm 0.06 ) (Table). The autoradiographs from the Epon sections confirmed the epithelial structure of the observed labelled 'progenitor' cells (Figure). No preferential site of DNA synthesis activity could be observed over mucosal crests or valleys in normal or distended gallbladders. After incubation with deoxyribonuclease, labelling on radioactive nuclei decreased to values that did not exceed 5 grains per nucleus.

Mitotic figures were observed in the normal gallbladder epithelium but the mitotic index was lower than $1 / 10000$. None of these mitotic figures was seen in the 1797 to 3203 consecutive epithelial
Table Mitotic and labelling index values in the epithelium of distended and control gallbladders

\begin{tabular}{|c|c|c|c|c|}
\hline $\begin{array}{l}\text { Age } \\
(y r)\end{array}$ & $\operatorname{Sex}$ & Total cell count & $\begin{array}{l}\text { Mitotic index } \\
(\%)\end{array}$ & $\begin{array}{l}\text { Labelling index } \\
(\%)\end{array}$ \\
\hline \multicolumn{5}{|c|}{ Distended gallbladders } \\
\hline $\begin{array}{l}82 \\
65 \\
68 \\
61 \\
63 \\
87\end{array}$ & $\begin{array}{l}\mathbf{M} \\
\mathbf{M} \\
\mathbf{F} \\
\mathbf{M} \\
\mathbf{F} \\
\mathbf{F}\end{array}$ & $\begin{array}{l}2437 \\
2671 \\
2432 \\
2274 \\
2481 \\
2328\end{array}$ & $\begin{array}{l}0 \\
0 \\
0 \\
0 \\
0.04 \\
0\end{array}$ & $\begin{array}{l}0.73 \\
0.90 \\
0.66 \\
0.66 \\
0.44 \\
0.56\end{array}$ \\
\hline \multicolumn{5}{|c|}{ Control gallbladders } \\
\hline $\begin{array}{l}22 \\
17 \\
40 \\
43 \\
39 \\
68 \\
64 \\
36\end{array}$ & $\begin{array}{l}\mathbf{F} \\
\mathbf{F} \\
\mathbf{F} \\
\mathbf{M} \\
\mathbf{M} \\
\mathbf{M} \\
\mathbf{M} \\
\mathbf{F}\end{array}$ & $\begin{array}{l}2173 \\
1929 \\
2488 \\
3203 \\
2052 \\
2134 \\
1797 \\
2342\end{array}$ & $\begin{array}{l}0 \\
0 \\
0 \\
0 \\
0 \\
0 \\
0 \\
0\end{array}$ & $\begin{array}{l}0.23 \\
0.21 \\
0.44 \\
0.06 \\
0.05 \\
0.19 \\
0 \\
0.09\end{array}$ \\
\hline
\end{tabular}

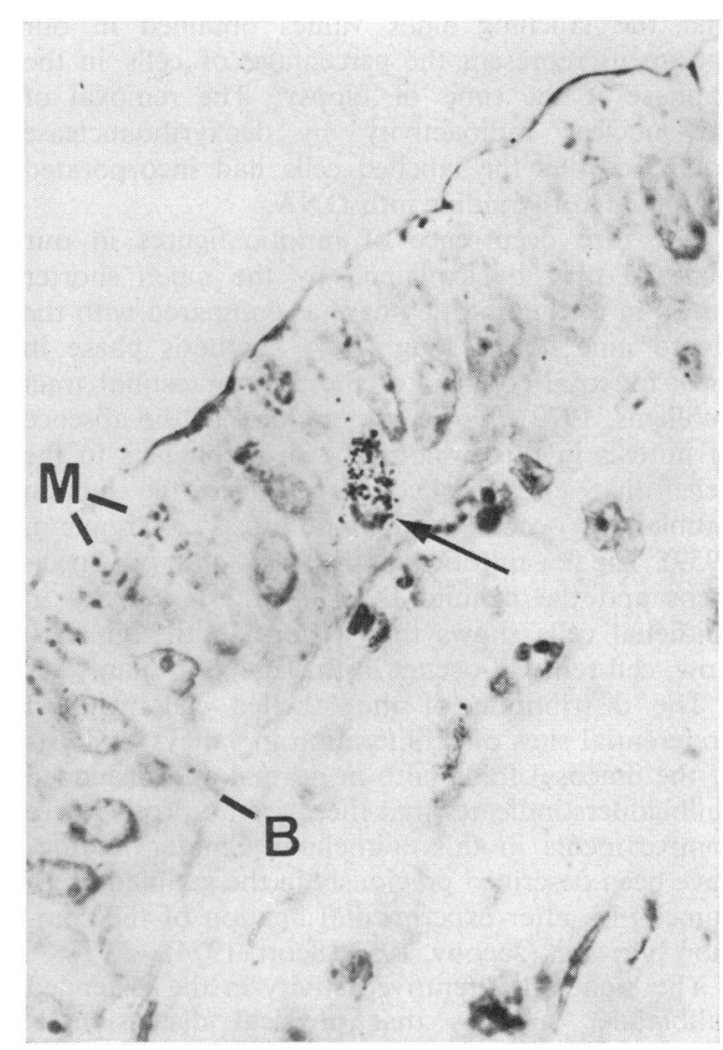

Figure Autoradiography of a distended human gallbladder after in vitro incubation with tritiated thymidine. One labelled epithelial cell is visible (arrow). Note the basement membrane $(B)$ of the epithelium, and the apical mucous granules $(M)$. Epon section, $1.8 \mu$ thick. Toluidine blue. 
cells observed for the estimation of the labelling indices. Therefore mitotic index in the controls was 0 and the higher mitotic activity in the distended gallbladders could not be demonstrated on a statistical basis.

\section{Discussion}

Our observations indicate that the cell turnover of the gallbladder epithelium is slower in man than in experimental animals. Indeed, labelling indices of $1.5 \%$ in rabbits (Scott, 1978) and of approximately $1 \%$ in small rodents (Scott, 1974) have been reported, whereas the mean labelling index values are six to 10 times lower in the normal human gallbladder. We have shown previously that the labelling indices measured after in vitro incubation of gastric and rectal mucosa with tritiated thymidine are similar to those obtained by using in vivo injection of the radioactive precursor to the same animals (Willems et al., 1970). Therefore, we were able to postulate that the labelling index values obtained in our specimens represent the percentage of cells in the $S$ phase at the time of biopsy. The removal of the nuclear radioactivity by deoxyribonuclease confirmed that the labelled cells had incorporated the tritiated thymidine into DNA.

The rare occurrence of mitotic figures in our material may be explained by the much shorter duration of the mitotic phase as compared with the six to nine hours' long DNA synthesis phase in most mucosal epithelia of the gastrointestinal tract (Willems, 1979). Earlier observation of the absence of mitosis in this organ has led histologists to the belief that epithelial cell renewal in the human gallbladder occurs through 'amitosis' (Bargmann, 1959). The few mitotic figures observed in our specimens and the definite DNA synthesis activity in epithelial cells shows that a normal, though very slow, cell renewal occurs in this tissue in man.

The distribution of the labelled cells without preferential sites of proliferation in valleys or crests of the mucosal folds both in normal and distended gallbladders indicates that there are no proliferative compartments in this epithelium. Similar findings have been described previously in the gallbladder of guinea-pigs after experimental ligation of the common bile duct (Jacoby, 1953; Scott, 1974).

The higher proliferative activity in the distended gallbladder suggests that physical distension is capable of stimulating the growth of the gallbladder mucosa. This implication is supported by the observations that stretching or local tension stimulates cell mitosis in tissues such as the skin (Billingham and Medawar, 1955), uterine wall (Leroy et al.,
1977) and urinary bladder (Goss, 1964). An alternative explanation of the effects observed in our patients with complete obstruction of the common bile duct could be that changes in the composition of gallbladder bile occur which, in turn, might influence the proliferative activity in the mucosa. The higher DNA synthetic activity observed in the non-lithiasic gallbladder of rodents on a lithogenic diet (Scott, 1978) and the fact that the intensity of the proliferative stimulation in the lithiasic human gallbladder is not correlated with the size or number of gall stones (Putz and Willems, 1978) provides some support for this hypothesis. The present observations do not exclude other explanations, such as indirect effects of the tumour or of jaundice, though no arguments in favour of these hypothetic mechanisms of mitotic stimulation are available.

The technical assistance of Mrs Y. Vansteenkiste is gratefully acknowledged. This work was supported in part by the Fonds voor Geneeskundig Wetenschappelijk Onderzoek and the Algemene Spaaren Lijfrentekas of Belgium.

\section{References}

Bargmann, W. (1959). Histologie und mikroskopische Anatomie des Menschen, p. 500. (3rd edition). Thieme: Stuttgart.

Billingham, R. E., and Medawar, P. B. (1955). Contracture and intussusceptive growth in the healing of extensive wounds in mammalian skin. Journal of Anatomy, 89, 114123.

Goss, R. J. (1964). Wound healing. In Adaptive Growth, p. 82. Academic Press: London.

Jacoby, F. (1953). Mitotic activity in the gallbladder epithelium of the guinea-pig after ligation of the common bile duct. Journal of Physiology (Lond.), 119, 21P-22P.

Leroy, F., Van Hoeck, J., and Bogaert, C. (1977). Effects of uterine distension and oestradiol on cell kinetics in the endometrial epithelium of ovariectomized rats. Cell Tissue Kinetics, 10, 437-445.

Putz, P., and Willems, G. (1978). Proliferative changes in the epithelium of the human lithiasic gallbladder. Journal of the National Cancer Institute, 60, 283-287.

Scott, A. J. (1974). Are there proliferative compartments in the gallbladder? Gastroenterology, 67, 1231-1237.

Scott, A. J. (1976). Lincomycin-induced cholecystitis and gallstones in guinea pigs. Gastroenterology, 71, 814-820.

Scott, A. J. (1978). Epithelial cell proliferation in diverse models of experimental cholelithiasis. Gut, 19, 558-562.

Willems, G., Galand, P., and Chretien, J. (1970). Autoradiographic studies on cell population kinetics in dog gastric and rectal mucosa: a comparison between in vitro and in vivo methods. Laboratory Investigation, 23, 635-639.

Willems, G., Vansteenkiste, Y., and Limbosch, J. M. (1972). Stimulating effect of gastrin on cell proliferation kinetics in canine fundic mucosa. Gastroenterology, 62, 583-589.

Willems, G. (1979). Cell proliferation and differentiation in the digestive tract. In Scientific Basis of Gastro-enterology, edited by H. L. Duthie and K. Wormsley. Churchill and Livingstone: Edinburgh. In press. 